\title{
Improving the environmental performance of the internal combustion engine by the use of in-cylinder catalyst
}

\begin{abstract}
The problems of using the inner surfaces of a combustion chamber as catalytic converters in order to reduce the harmful exhaust emissions were discussed in this paper. The proper choice of the catalyst is one of the most important issues. The interaction between the burned mixture and the catalyst is not limited by the kinetics of the chemical reactions but depends primarily on the flow rate of the reactants to the catalyst surface during combustion. The lifespan of a catalytic layer is determined by the application technique, where plasma spraying is the most popular and most accessible method. However, when it comes to the catalytic coating durability, it is not an efficient option, as ion implantation is indicated shows greater potential in this respect. In this research the coating of aluminumtitanium and chromium-nickel have been applied to the engine head and the piston crown. Then the modified catalytic parts were used in a CI combustion engine and the obtained emission results were compared with the reference results. Another set of tests was performed for an SI engine, powered with gasoline and methane, where the piston crown was covered with a thermal layer of zirconium oxide and a catalytic layer of platinum. The beneficial effects of these in-cylinder catalysts on exhaust emissions and the possible problems in the wide spread use of such solutions have been presented.
\end{abstract}

Key words: IC engine, catalyst, in-cylinder catalysis

\section{Introduction}

Reciprocating internal combustion engines are now a common source of power in the drives of motor vehicles, machinery and equipment. They were initially used as stationary engines, but then, thanks to their many advantages, they started also being used in vehicles. The pursuit to get more and more engine power output, improved work indicators, to reduce the engine weight and its harmful effects on the environment are just some of the targets for engines today. All of these aspects also substantially affect the engine development process, including its individual components and subsystems. These requirements are also the reason driving change in the proper operating method of internal combustion engines, with the aim to achieve these benefits while maintaining a low environmental impact.

For an internal combustion engine, the nature of its operation determines the formation of harmful exhaust gases, where the proper execution of the combustion process tends to be the primary source of these pollutants. Increasing emphasis on reducing the negative impact of combustion engine vehicles on the environment, both from the legislative institutions of individual countries as well as their communities, drives the search for ever more sophisticated technical solutions for the internal combustion engine, which will ensure environmental impact reduction and allow meeting current emission standards. Among such efforts, the ones that reduce the emissions in exhaust gases after they leave the internal combustion engine are essential, i.e. the advanced exhaust aftertreatment systems.

Due to the nature of operation of such systems (obtaining the high required operational temperature) places them ever closer to the engine. However, these activities are aimed at reducing the pollutants that have already formed (been produced) in the combustion engine. On the other hand, careful consideration should be given to measures which are technically feasible and which would influence the reduction of pollutant production at their source - that is, in the combustion chamber of the engine - by adding catalysts as close to the combustion process as possible.

\section{The concept of using an in-cylinder catalyst}

The process of combustion and heat release in combustion engines generates effects of a physical and a chemical nature, that to a large extent determine the engine operational properties. The most essential physical effect of the combustion process for the engine, is primarily the combustion quality (how much energy contained in the fuel is released), and how effectively it is used, the value of the crank dynamic loads the and the noise generated. The chemical effects mainly relate to the composition of the exhaust gases, especially the content of toxic substances. Currently, due to the environmental protection regulations the control of these substances is among the main requirements for the operation of internal combustion engines.

The conditions in which combustion occurs, should primarily ensure the complete release of fuel energy (complete combustion) with the fullest possible use of the air and maintaining the exhaust gases as pure as possible. From the engine, thermodynamic cycle analysis, it follows that the utilization efficiency of the heat released in the engine during combustion is related to its position in time. As a result the conditions required for the full fuel energy release, along with its use, and for obtaining low dynamic crankshaft loads while maintaining low noise level oppose each other. Therefore, every technical solution to this problem must be a matter of compromise between these aspects. Another factor affecting this compromise is the exhaust gas composition, which must now meet the established legal requirements.

In the first stage of self-ignition delay a stream of atomized fuel is subject to preparatory reactions which result in spontaneous combustion centers appearing in different locations on the fuel stream surface. Oxidation in this stage can be represented as a slow burning process without a visible flame or pressure increase. This process is exothermic, so heat is produced, where part of it heats the air-fuel mixture, and part is dispersed to the combustion chamber 
wall. Heating the mixture accelerates the reaction, which leads to further production of heat and oxidation. Under certain conditions, the amount of heat generated becomes equal to the amount of heat dispersed, leading to a thermal balance which corresponds to the mixture ignition temperature. Such thermal equilibrium quickly disappears as the mixture is heated further as a result of the increasing pressure and temperature, which finally results in the selfignition and combustion of the fuel.

For the reaction to start, collision of reactive particles is necessary. In fact, not all collisions cause a reaction to occur between the particles. The particles have finite speeds, which means that only a certain number of them causes a reaction to occur. Effective collisions are defined as only those collisions, where the total collision energy is higher than the average energy, specific for a given temperature. The activation energy is the energy surplus, which molecules need to have in the moment of impact in order to enter into a chemical reaction, and is the primary factor in determining the course of that reaction. The lower the activation energy, the greater the reaction rate constant and the faster the reaction. To help overcome the energy barrier associated with the activation energy, either additional energy can be delivered to the reaction (for example through heating) or a substance can be used (a catalyst), which readily reacts with the substrate (lower activation energy) and the resulting compound can easily transform into the final product (also low activation energy). After the substrates transform into products the catalyst completely regenerates, thus it is possible to sometimes encounter the claim that the catalyst is a substance not taking part in the reaction but merely facilitating its course.

Based on such analysis it can be concluded that the improvement of environmental and economic operating parameters of combustion engines mainly depend on the proper execution of the combustion process, which is highly dependent on the activation energy and the presence of a catalyst that increases the chemical reaction rate. Therefore, it is proposed that such "internal" catalyst is used as a structural element of the combustion chamber.

\section{Possible applications overview}

Studies by Karuppasama and Mageshkumara [5] related to engine components coated with aluminum, titanium, nickel and chromium compounds deposited via plasma spraying (Fig. 1). The parameters of the investigated engine were as follows:

- four-stroke single cylinder CI engine,

- cylinder diameter $-80 \mathrm{~mm}$,

- piston stroke $-110 \mathrm{~mm}$,

- compression ratio - 16 ,

- liquid cooling,

- engine speed (const.) - $1500 \mathrm{rpm}$.

The study was conducted for fixed engine speed and variable load. The concentration of carbon monoxide (Fig. 2), hydrocarbons (Fig. 3) and nitrogen oxides (Fig. 4) have been determined as well as specific fuel consumption (Fig.

4) for the following test conditions:

- elements of the engine head and piston crown without a catalytic layer,
- parts of the engine head and the piston crown covered with aluminum and titanium compounds (Al-Ti),

- parts of the engine head and the piston crown covered with nickel and chromium compounds (Ni-Cr).

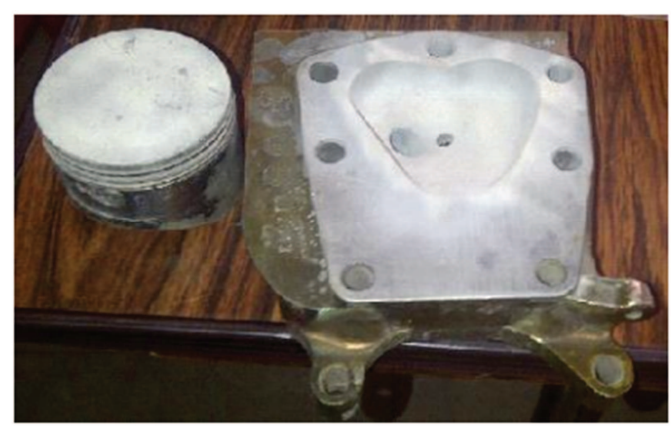

Fig. 1. The elements of engine covered by means of plasma spraying

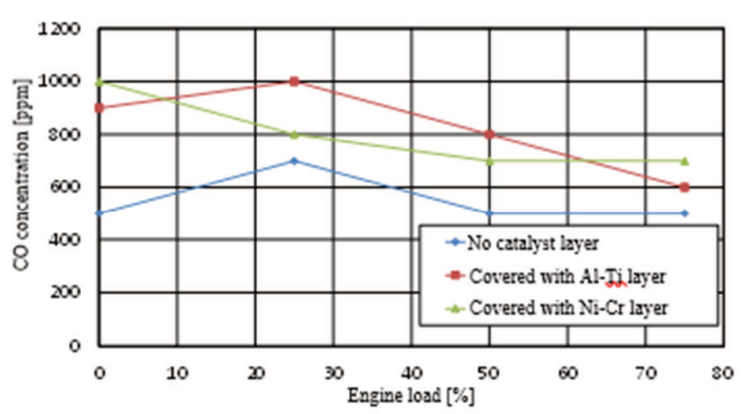

Fig. 2. The concentration of carbon monoxide as a function of engine load

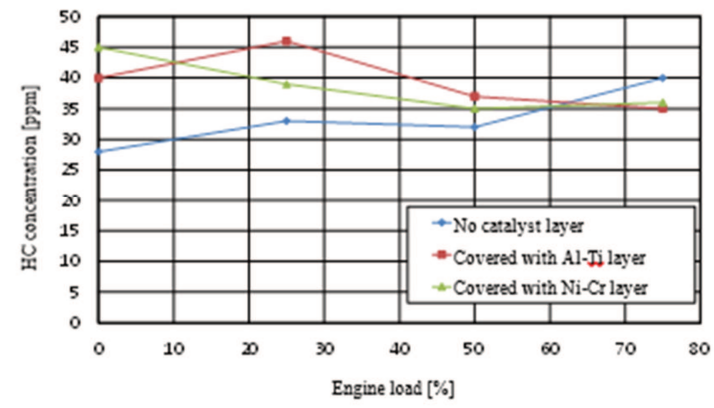

Fig. 3. The concentration of hydrocarbons as a function of engine load

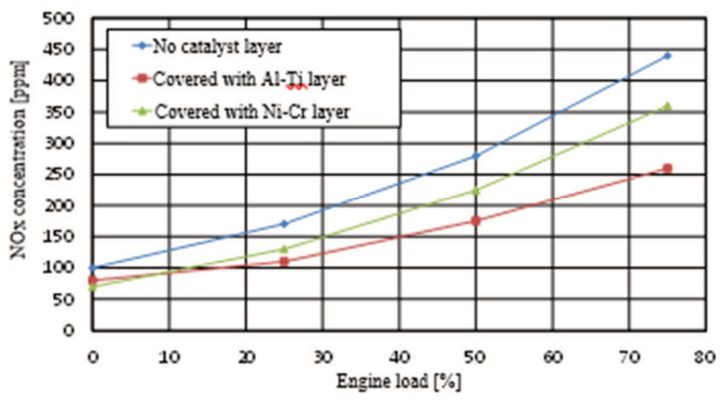

Fig. 4. The concentration of nitrogen oxides as a function of engine load

Based on the research results, it has been confirmed that the $\mathrm{Al}-\mathrm{Ti}$ and $\mathrm{Ni}-\mathrm{Cr}$ catalytic layers:

- adversely affect the concentration of carbon monoxide (CO) and hydrocarbons (HC) in the exhaust gas. For hydrocarbons, a $10 \%$ reduction has been observed for the highest engine loads, 
- reduce the emission of nitrogen oxides $\left(\mathrm{NO}_{\mathrm{x}}\right)$ in the entire range of engine loads by approx. $30 \%$, which is of particular importance for compression ignition engines,

- reduction in specific fuel consumption by about $15 \%$ over the entire tested engine load range.

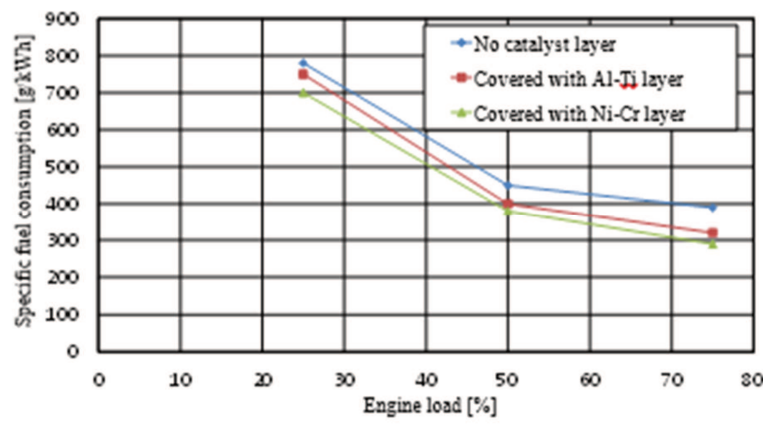

Fig. 5. Specific fuel consumption as a function of engine load

Research by Soltic and Bach [9] related to the issue of internal catalysts used in spark ignition engine powered with methane. The basis for the performed analysis of this issue was the difficulty of methane reduction in the catalytic reactor, due to the fact that it is the most stable molecular hydrocarbon, while keeping the methane in the catalytic reactor at an excess air ratio greater than 1 .

Two pistons with different catalytic layers were tested: - platinum layer with a thickness of $20 \mathrm{~nm}$,

- porous zirconium oxide layer with a thickness of 0.6 $\mathrm{mm}$ to increase the temperature of the catalytic surface and thus catalyst reactivity (Fig. 6). The catalytic platinum layer was applied in a magnetron sputtering process (Fig. 6).

Figure 7 shows the surface of the piston after applying a zirconium oxide layer via thermal spraying. The desired thickness of the thermal surface was obtained through grinding.

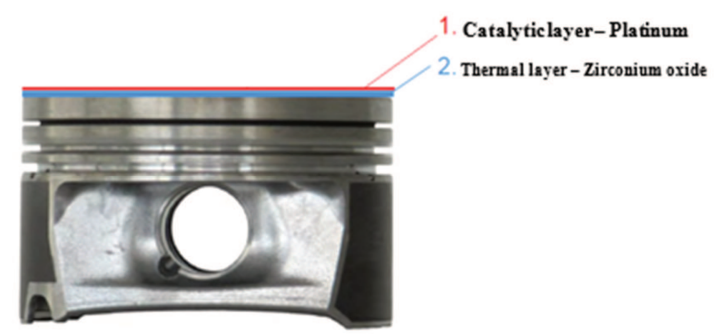

Fig. 6. Method of covering the piston with catalytic and thermal surfaces

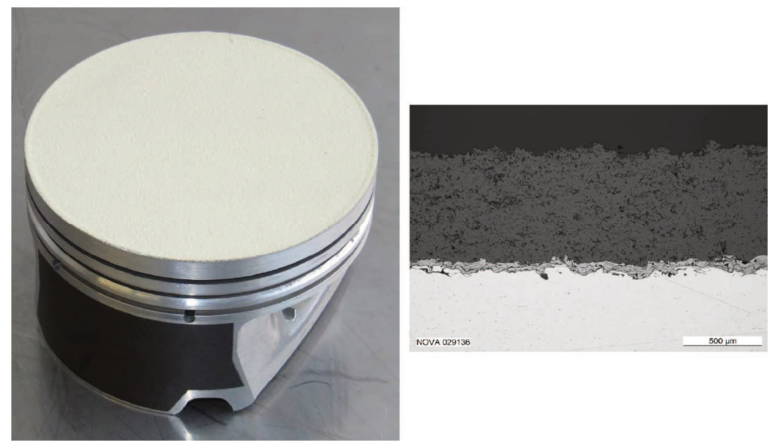

Fig. 7. Piston surface coated with zirconium oxide
The test was carried out on a research station that enabled maintaining stable air parameters (temperature and humidity) and the measurement of engine performance as well as hydrocarbons concentration in the exhaust gas. In the study a 4cylinder, spark ignition engine fueled with gasoline and methane with a displacement of $2 \mathrm{dm}^{3}$ was used.

Measurements of hydrocarbons, carbon monoxide and nitrogen oxides concentrations in exhaust gas were performed at the following parameters: lubricating oil temperature greater than $90^{\circ} \mathrm{C}$, air temperature of $24^{\circ} \mathrm{C}$, humidity of $47 \%$. Measurements were taken at $2500 \mathrm{rpm}$ for different values of the excess air ratio $(0.9,1.0,1.1)$ and various ignition timing settings. After 28 hours of operation, the catalytic coating was evaluated for signs of wear. Damp areas formed by the effects of the engine oil have been found on the piston crowns (Figure 8).

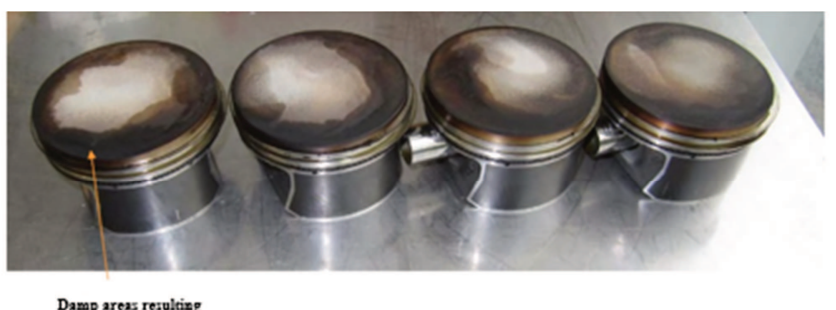

Damp areas resuling
from the lubricating oil

Fig. 8. State of the catalytic surface after 28 hours of operation

In this research the authors did not notice any significant changes in the nitrogen oxides concentration in the exhaust gas, regardless of the fuel used and the excess air ratio (Fig. 9). Similar results have been reported with respect to the carbon monoxide concentration in the exhaust gas - irrespective of the fuel used and the excess air ratio there were no significant concentration changes (Fig. 10).

An increase in the hydrocarbons concentration has been confirmed regardless of the fuel used and the excess air ratio value - this was a result of the catalytic coating application. The result of the study was the adsorption and desorption properties determination of the thermal coating layer (zirconium oxide). With a high internal cylinder pressure, the coating takes in a significant mass of methane (1.74 $10^{-3} \mathrm{~g}$ per cylinder). At low pressures, methane is released directly into the exhaust, increasing its content as a result (Fig. 11).
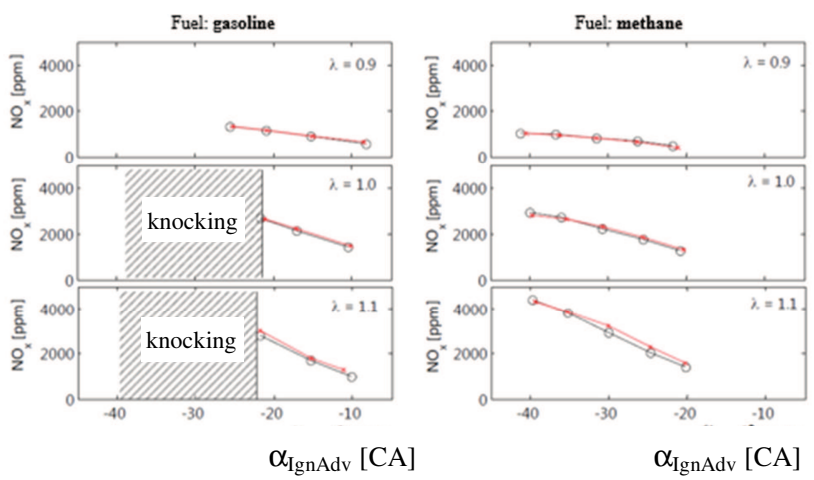

Fig. 9. Nitrogen oxides concentration in the exhaust gas of petrol and methane fueled engine 


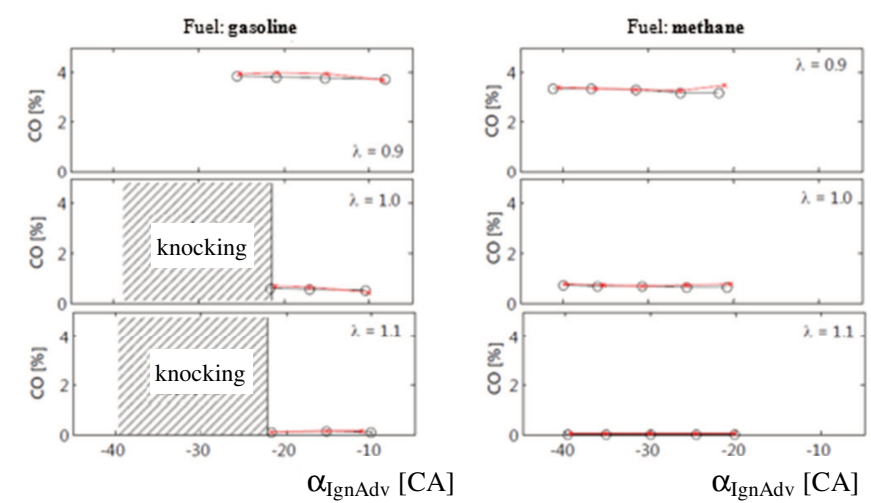

Fig. 10. Carbon monoxide concentration in the exhaust gas of petrol and methane fueled engine
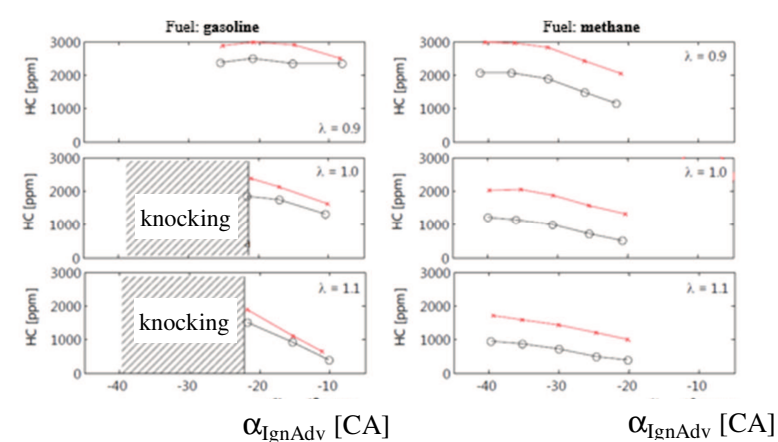

Fig. 11. Hydrocarbons concentration in the exhaust gas of petrol and methane fueled engine

The study concluded that the thermal and catalytic layers would withstand the thermal and mechanical stress present in the cylinder of the spark-ignition engine. There was a significant hydrocarbons concentration increase in the exhaust gas due to the use of a piston covered with a catalytic layer. There were no changes in concentrations of other pollutants (nitrogen oxides and carbon monoxide).

\section{Conclusions}

From the presented overview of the possibilities of using in-cylinder catalysts in internal combustion engines, the following conclusions can be drawn:

- One of the most important issues is the choice of an appropriate catalytic converter depending on the engine type (spark ignition, compression ignition). Individual elements or compounds are characterized by different operating temperature ranges in which they reach the highest efficiency. Due to the change in the catalytic surface efficiency depending on the temperature in the cylinder, ensuring a sufficiently high catalysts efficiency for the entire engine load range is challenging. This is due to the fact that the temperature in the cylinder also changes depending on the engine load.

- The interaction between the combustible mixture and the catalyst is not limited by the kinetics of the chemical reactions, but rather depends on the rate at which the reactants are delivered to and from the catalyst during the combustion process. This aspect can be improved by introducing turbulence into the cylinder charge.

- The lifespan of the catalytic surface depends on the coating method. Plasma spraying is the most common and most readily available, but it does not work well for catalytic coating. Ionic implantation is most often considered as a high potency solution for this problem.

\section{Bibliography}

[1] BANNIKOV, M.G., DRAPER, P.H, CHATTHA, J.A. et al. Reduction in $\mathrm{NO}_{\mathrm{x}}$ emission of diesel engines by in-cylinder catalysis. Proc. Instn Mech. Engrs, Part A: J. Power and Energy. 2003, 217.

[2] GUO, H., MURAKAMI, H., KURODA, S. Thermal cycling behavior of plasma sprayed segmented thermal barrier coatings. Materials Transactions. 2006, 47(2), 306-309.

[3] HEJWOWSKI, T. Comparative study of thermal barrier coatings for internal combustion engine. Vacuum. 2012, 2(12).

[4] HU, Z., LADOMMATOS, N. Reduction of unburnt hydrocarbon emissions from spark ignition engines using incylinder catalysts. Proc Instn Meeh Engrs, Part D: Journal of Automobile Engineering. 1996, 210.

[5] KARUPPASAMY, K., MAGESHKUMAR, M.P., MANIKANDAN, T.N., et al. The effect of thermal barrier coatings on diesel engine performance. ARPN Journal of Science and Technology. 2013, 3(4).
[6] MELlO, J.P., BEZAIRE, D., SRIRAMULU, S., WEBER, R. Performance and economics of catalytic glow plugs and shields in direct injection natural gas engines for the next generation natural gas vehicle program. Final report. $\mathrm{Na}$ tional Renewable Energy Laboratory. NREL/SR-54034286, 2003.

[7] NEDUNCHEZCHIAN, N., DHANDAPANI, S. Effects of in-cylinder catalytic coating on the performance of a twostroke spark ignition engine. Indian Journal of Engineering \& Materials Sciences. 2001, 8, 1-7.

[8] NORMAND, B., FERVEL, V., CODDET, C., NIKITINE, V. Tribological properties of plasma sprayed aluminatitania coatings: role and control of the microstructure. Surface and Coatings Technology. 2000, 123, 278-287.

[9] SOLTIC, P., BACH, C. Catalytic piston coating. Conference Gas Powered Vehicles. Berlin 30.09-1.10.2010.

[10] TAYMAZ, I., CAKIR, K., GUR, M., MIMAROGLU, A. Experimental investigation of heat losses in a ceramic coated diesel engine. Surface and Coatings Technology. 2003, 169-170, 168-170.

\author{
Monika Andrych-Zalewska, MEng. - Department \\ Vehicles Engineering at Wroclaw University of \\ Science and Technology. \\ e-mail: Monika.Andrych@pwr.edu.pl
}

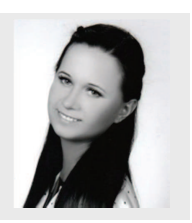

